\section{Microscopic Artifacts In The History Of Biology}

Alan Eugene Davis, Marianas High School, Saipan adavis@saipan.com

I am posting a summary of responses to my request to the Microscopy Listserver on 3 December 2001, for information about any roles microscopic artifacts may have played in the history of biology. I posted my own experience regarding Sidney Hickson's description of reproductive events in Millepora spp. (A copy of my somewhat lengthy post is enclosed at the end of this summary.)

To be fair to Sidney Hickson, who drew and described the incredible, imagined sequence of reproductive events in Millepora spp. as mentioned in my original, I believe that he did print a retraction of the findings in that paper.

Gareth Morgan (whose contribution is mentioned below) offered the following remark: We tend to see what we expect might possibly be there and consciously or unconsciously ignore the rest as 'noise' - perhaps a natural action but also potentially dangerous.

Maureen A. Peterson offered a similar remark, which I took as personal advice: Lesson? I better keep my eyes and my mind open.

Both Volker Brinkmann and Mike Dalbey called attention to the "homunculus" (little man-shaped pre-embryos) which were reported in the 18 th Century in human sperm.

Volker Brinkmann: The first microscopic misinterpretation was probably that by Antoni van Leeuwenhook analysing human sperm. He was convinced to see little men with heads, arms and legs swimming around. There are some nice drawings of that.

Mike Dalbey: Surely the most famous misinterpretations of microscopical observations are those recorded in drawings made by preformationists in the 18th Century of the "homunculus" in the head of human sperm. Several of these drawings are commonly reprinted in textbooks as cautionary examples.

Mike Dalbey further pointed out several interesting examples, including a contemporary issue, the putative bacteria fossiles in the martian meteorite:

For a discussion of a common histological artifact see "Multinucleate Plant Cells" by Burkholder and Mc Veigh (1941) in vol. 68 of the Bulletin of the Torrey Botanical Club p. 395.

You should also check out what the web has to offer on the history of Royal Rife and the Rife Microscope.

Finally, evidence seems to be accumulating that the "nanobacteria" observed by EM in the martian meteorite are artifacts.

Maurreen A. Peterson (Mape@mail.ifas.ufl.edu) posted concerning a disease of grapes, a case of failure to see the etiological agent, which was there all the time:

Being a Plant Pathologist, the best I can think of is the story of Pierce's disease of grapes, which was of unknown etiology for a long time. Forgive me for not seeking details from the literature.

At one time it was proposed to be caused by a virus. Extensive light microscope work missed the true cause- a bacterium. After elucidation of the pathogen, I am told that upon review of work previously done, the bacterium WAS there to be seen, but was missed.
Upon a similar vein, MLO's in plants were not recognized in TEM work until a human or animal pathologist saw micrographs of MLO's in plant tissue, and was readily able to say what they were. Anecdotal, but food for thought.

Two similar misinterpretations of existing evidence were pointed out by Gareth Morgan (<Gareth.Morgan@impi.ki.se>). The first regarded Helicobacter pylori, a causitive agent for gastric ulcers.

Not sure if this one fits the bill but it is a similar one to the grape disease story by Maureen Petersen. The one I mean is the discovery/description of Helicobacter pylori in human gastric biopsies in the early 80's (when it was given the name Campylobacter pylori). It had been there all of the time but had been disregarded as 'stuff'.

Gareth suggested a google search might reveal more information, and indeed it did: over 82,000 hits. I hope I will be forgiven for quoting one site in part:

Although they were the first to succeed in establishing a link between bacteria and ulcers, the Australians were not the first to try. Since the time of Robert Koch in the late 19th century, microscopists observed curved bacteria among the cells under the mucus lining of the stomach, particularly in and around ulcer craters. No one had ever succeeded in isolating the microorganisms, however, and their presence had been explained away as artifact or postmortem contamination. Besides, it was thoroughly accepted among clinical microbiologists of the time that it was unlikely that bacteria could live and grow in the strongly acidic environment of the human stomach.

Warren, a pathologist who examined gastric biopsies, also observed the curved rod-shaped bacteria under his microscope. After examining many such specimens, he realized that the bacteria were always present in tissue that showed signs of inflammation, that the number of organisms correlated with the degree of the inflammation present, and that they occurred in half of the routine gastric biopsy specimens he examined. Convinced that his observations were significant and merited further investigation, he kindled the interest of Barry Marshall, then a trainee in internal medicine, and together they set out to isolate the source of the infection. [This site is: http://www faseb.org/opar/pylori/pylori.htm/]

Gareth also suggested a similar misreading may have been involved with the finding of Actinomyces in cervical smear material. I was unable to find any clear elucidation of such events: however, one site mentioned that care should be taken by the pathologist in diagnosing "atypical Mycobacteria" due to possible presence of Actinomycetes.

H. F. Moura Nunes posted about another possible case:

I am not sure of that. But I heard some years ago that the first information about the structure of poliovirus - in the early days of the electron microscope - was that they were long filamentous structures. Some time later it has been seen that the filamentous structures were in fact bacterial flagella.

Tina Carvalho posted a long discussion of a personal experience regarding another real structure that had been interpreted as an artifact. The experience must be re-posted in its entirety, in spite of its length:

Although $/ \mathrm{m}$ sure there are examples of misinterpretation of artifacts that have been perpetuated for many years, I can offer here a story of the flip side. This is about what appeared to be a well-known artifact that turned out to be, in fact, a surprising real structure. It's also an embarrassing personal story!

Continued on page 20 


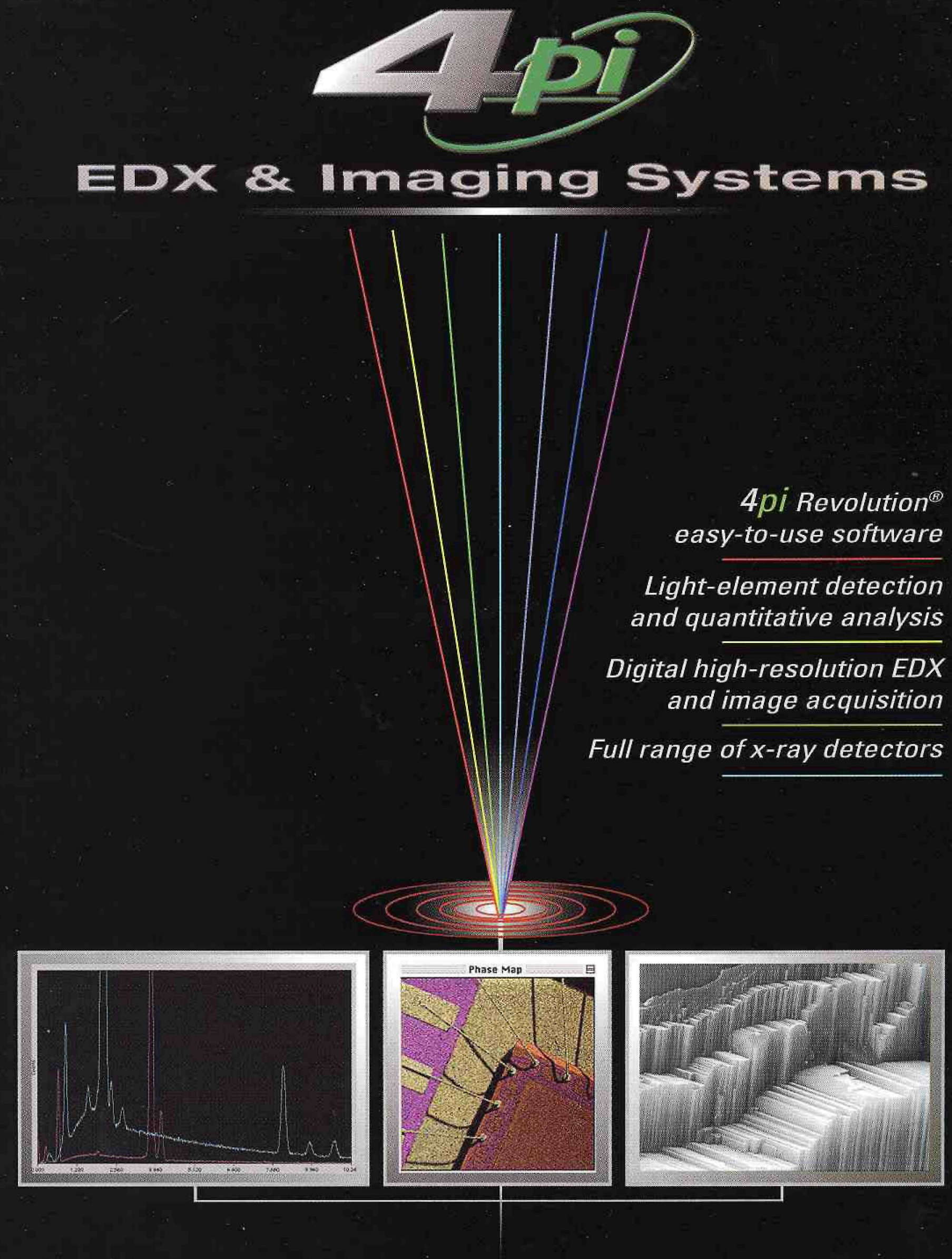


Microscopic Artifacts In The History Of Biology Continued from page 18

An undergraduate student was working with some colleagues who were studying the behavior and neurophysiology of the escape response of several species of planktonic copepods (small crustaceans). They had reams of data and were beginning to characterize the responses of the animals to different kinds of stimuli. Each species had it's own characteristic response, but a general picture was beginning to form. There appeared to be two different classes of response though, one type particularly puzzling. The undergrad spent some time in the EM facility with me, using SEM to describe the sensory setae. She expressed an interest in trying TEM and so we went through fixation, embedding, sectioning, etc. I had worked on the tiny beasts for close to 10 years and had found some interesting structures that I worked on from time to time. Copepods were difficult to fix, some species more so than others. So I had concentrated on the "pretty" ones and temporarily given up on the "ugly" ones - the ones with all those myelin body artifacts that I just couldn't seem to avoid. Finally it was time to try to work on them again, so I gave this one particularly difficult species to the undergrad to try to fix and section. She came to me with micrographs, wondering what in the world were those squiggles she saw. I patiently explained that myelin bodies were a fixation artifact, produced when lipids became mobile during fixation, then reformed in these "onion bodies". I sent her back to work to try again, and she came up with the same results. "What if they aren't an artifact?" she kept asking. I explained that invertebrates do not have such membranous structures; they were artifactual. I brought out the books and papers about myelin body artifacts. I brought out the books and papers that said invertebrates do not have membranous wrappings around their axons. She was unconvinced. In a hurry one day when she was really bugging me I dug through my files and found the decade-old folder to show her l'd seen the same thing - an artifact. "But there's an axon in the middle of each one", she protested, not knowing that was "impossible". I glanced at them impatiently and saw that she was right, but she was running off to class.

Later that day we looked closely and decided that, indeed, the images were a real mess and difficult to interpret, but there was a faint possibility that these weren't classic myelin body artifacts. Whatever it was was certainly reproducible, and these forms appeared every time in the antennal nerve. So we emailed the PIs of the project and told them we might have myelinated axons in the difficult-to-interpret species. It was April 1. April Fools' Day, the undergrad's name was April, and they thought it was a joke. After all, the dogma is that invertebrates don't have myelin! Check any biology book.

But by the next day they realized that myelin (OK, "myelinlike structures" for you purists) would instantly and completely explain 10 years' worth of puzzling data.

It took awhile to prove to ourselves (mainly me, since l'd been repeating the dogma for many years) that these structures were real, orderly, and extensive wrappings of membrane around the axons. It took ultrarapid cryofixation and cryosubstitution to really show that the artifactual bodies that had plagued a number of people working on these critters were in truth these surprising, dogma-busting structures.

We made the April the first author on the Nature paper, which came out in April 1999.

I don't take anything for granted anymore! The lesson is: keep an open mind.
For more on the copepod story-Copepod neuroecology http://www.pbrc.hawail.edu/ petra/copepod.htm!

Finally, perhaps appropriately, I include my original posting:

I am interested in gaining insight into the role of microscopic artifacts in the history of biology. May 1 impose on list members to contribute particularly glaring examples of misinterpreation of biological facts due to improper microscopic technique? I apologize if this is off-topic or a waste of bandwidth. Let me provide the first example of a misinterpretation and request your assistance in learning whether this was due to improper use of the microscope, or perhaps even malfeasance: Sidney Hickson's early work on Millepora spp. (Cnidaria:Hydrozoa) fire corals. It seems an incredible lapse, a wholly fabricated natural history account, one that persisted for a considerable period in the fabric of the mythology of biological knowledge. I am interested because reproduction of Millepora platyphylla is the subject of incompleted thesis research of mine.

Hickson published a report on reproduction of "Millepora" around the end of the 19th Century. (Among his other errors he synonomyized all species of Millepora as ecomorphs of one, $M$. alcicornis.) In this report, which I do not have available at this time, he included several plates of drawings depicting a putative sequence of reproductive events in this organism. We now understand that his depiction is not even close to the way that Millepora spp. (which were later redesignated as proper individual species through painstaking work by Boschma--notwithstanding the issues recently raised by molecular work) reproduce. The depiction involved dozens of drawings, and a sequence of events based on a misinterpretation of what are apparently artifacts. Hickson (of Cambridge University) worked extensively in the field, including Indonesia and the Philippines. Was his microscopic work done in the field? Are members of this list enlightened as to Hickson's methods? Hickson's erroneous drawings of the medusae of Millepora lived on for over $3 / 4$ of a century in virtually every invertebrate Zoology textbook published until the late 1980 s or 1990s. His erroneous description of the medusa of Millepora as lacking a velum led to the designation of a separate branch of hydromedusae by Mayer, as the only hydrozoan medusa without a velum. My unpublished observations in the 1980 s as well as published observations by John Lewis of McGill University showed that the medusae of Millepora spp. clearly possess a velum. I apologize for monopolizing the bandwidth. I hope this is as fascinating a topic for others as for myself, and not considered offtopic.

Paul R. Hazelton, Ph.D (Paul Hazelton@umanitoba.ca) responed to this summary, asking:

...nobody said anything about the rule of 48 ?

A long browse on this topic led to, among other sites: http://denbeste.nu/entries/00001189.shtml, which I quote:

A famous aphorism in science is the Rule of 48: "Scientists can't count." When the chromosomes were first discovered, someone inevitably counted those from human cells and announced that there were 48 of them. That became the number which appeared in reference books and encyclopedias and school texts. Then someone noticed that the proper number was really 46.

I have steadily endeavored to keep my mind free, so as to
give up any hypothesis, however much beloved - and I can-
not resist forming one on every subject - as soon as facts
are shown to be opposed to it. -- Charles Darwin (1809- 


\section{The Centaurus}

\section{FT-IR microscope.}

\section{Unmistakably}

family-with

a personality

all its own.

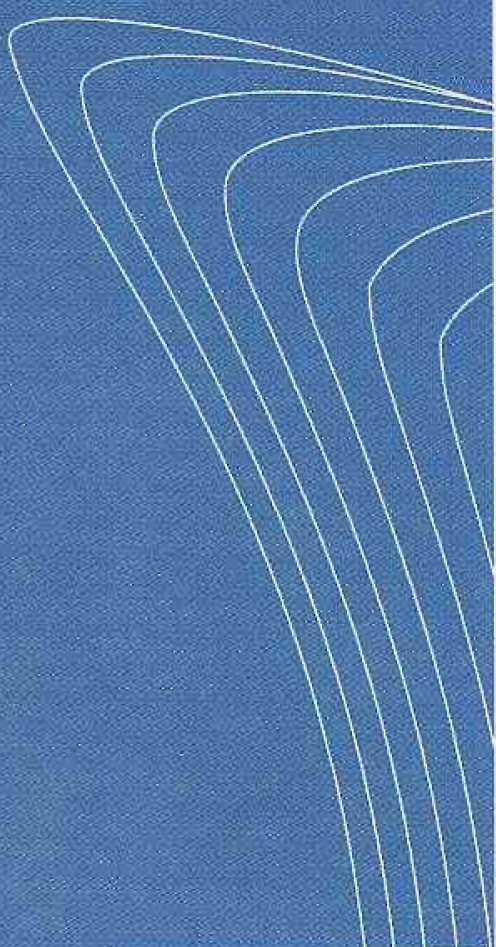

Meet our newest micro sampling family member, the Centaur $\mu s^{\mathrm{T}}$ IR microscope. At first glance, you'll notice it's compact and multitalented. A closer inspection will also reveal its rugged workhorse persona.

The talented micro sampling family from Thermo Nicolet embraces both IR and Raman technologies. With such an impressive lineup, you'll find one instrument with the exact capabilities to meet your needs.

To see which member of our micro sampling family best suits your situation, visit www.thermonicolet.com. Better yet, call us. Together, we'll make a perfect match.

Thermo Nicolet, 5225 Verona Road, Madison, W/ $53711-4495$ Phone: $1-800-201-8132$ or 1-608-276-6100, Fax: 1-608-273-5046

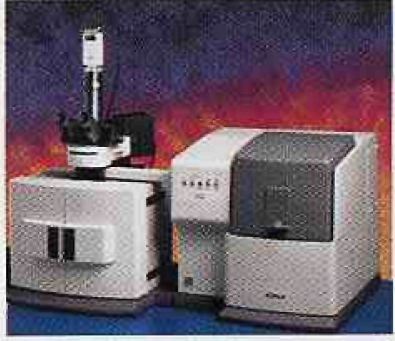

Almega' Dispersive Raman System

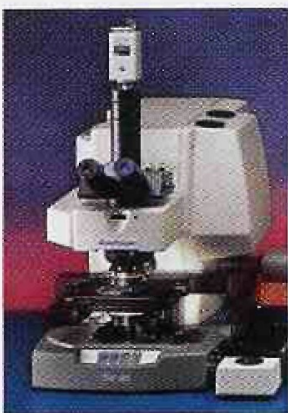

Continum " IR Microscope

\section{ThermoNicolet}

